\title{
Is there a potential role for CMR in deciding appropriateness for ACID placement?
}

\author{
Hayah Kassis ${ }^{1 *}$, Brandon M Mikolich, Robert W Biederman, Ronald J Mikolich² \\ From 18th Annual SCMR Scientific Sessions \\ Nice, France. 4-7 February 2015
}

\section{Background}

It is a class I indication to place AICDs in patients with ischemic or nonischemic cardiomyopathy with a left ventricular ejection fraction $(\mathrm{LVEF}) \leq 35 \%$. Most commonly, the need is determined by LVEF measurements on 2-D echo. This practice was utilized prior to cardiac MRI (CMR) establishment as the LVEF "gold standard" modality. Transthoracic echocardiography is still widely employed because of its wide availability and perceived cost savings. This study was designed to compare LVEF by both 2-D and CMR prior to AICD, along with analysis of comparative Medicare reimbursement.

\section{Methods}

Patients in a multi-institutional cardiac imaging database who underwent AICD implantation according to class I guidelines were queried for pre-AICD 2-D echo and CMR exams, constituted the study population. LVEF by 2-D and CMR were assessed for concordance for LVEF $<35 \%$. The discordant patients were categorized as higher or lower CMR LVEF, relative to 2-D LVEF. Using 2012 Medicare reimbursement data for Western Pennsylvania, imaging reimbursement prior to AICD implantation per 100 patients was calculated.

\section{Results}

131 patients met entry criteria for this study. Seven of 131 patients (5.3\%) had LVEF > 35\% on CMR, but $\leq 35 \%$ on 2-D. Eleven of 131 patients (8.4\%) had LVEF $\leq 35 \%$ on CMR, but $>35 \%$ on TTE. Overall, 18 of 131 patients (13.7\%) showed discordance between CMR and 2D and may have had an incorrect decision for AICD based on 2-D echo alone. The reimbursement of a Structure/Function CMR exam (codes 75557 and 75565 ) was $\$ 30,653$

${ }^{1}$ Cardiology, Allegheny General Hospital, Pittsburgh, OH, USA Full list of author information is available at the end of the article per 100 patients, while 2-D/Doppler exam (codes 93325 and 93306) was $\$ 35,578$ per 100 patients.

\section{Conclusions}

Of patients undergoing AICD implantation for primary prevention, $5.3 \%$ had an LVEF $>35 \%$ on CMR, and may not have required an AICD. Conversely, 8.4\% of patients would not have received an AICD based on 2-D results. For patients with cardiomyopathy undergoing assessment for the need of AICD for primary prevention, CMR is likely more accurate and is a cost saving imaging strategy for evaluation of AICD implant candidates with current reimbursement rates in the United States.

\section{Authors' details}

${ }^{1}$ Cardiology, Allegheny General Hospital, Pittsburgh, OH, USA. ${ }^{2}$ Cardiology, Sharon Regional, Sharon, PA, USA.

Published: 3 February 2015

doi:10.1186/1532-429X-17-S1-P229

Cite this article as: Kassis et al:: Is there a potential role for CMR in deciding appropriateness for ACID placement? Journal of Cardiovascular Magnetic Resonance 2015 17(Suppl 1):P229.

Submit your next manuscript to BioMed Central and take full advantage of:

- Convenient online submission

- Thorough peer review

- No space constraints or color figure charges

- Immediate publication on acceptance

- Inclusion in PubMed, CAS, Scopus and Google Scholar

- Research which is freely available for redistribution 